\title{
Sliding Mode Controller for DC to DC converters and Performance Comparison with Conventional PID and FOPID Controllers
}

\author{
Aseem $K^{*}$ and Selva Kumar S \\ Department of Electrical and Electronics Engineering, Amrita School of Engineering, Coimbatore, Amrita Vishwa Vidyapeetham, \\ India \\ Received 19 April 2020; Accepted 14 July 2020
}

\begin{abstract}
The mathematical modelling of automatic feedback control of four dissimilar types of basic DC-DC converters based on Sliding Mode type Controller (SMC) is discussed in this paper. The execution of the SMC is compared with standard PID controller and Fractional Order based PID (FOPID) controllers. The state space modelling of converters is determined and subsequently the Sliding Mode (SM) controller is implemented for chosen converters such as buck type, boost type, buck-boost type and Double Input and Single Output (DISO) type DC to DC converters. The experimental analysis was carried out in MATLAB Simulink platform. The suitable sliding surface is chosen and based on this; the SMC controller model is derived for each type of converter. The output of each converters is plotted. The various time domain specifications are tabulated and compared with three types of controllers. The usefulness of each control strategies is tested by sufficient simulation analysis.
\end{abstract}

Keywords: Buck-converter, Boost type converter, Buck-boost converter, DISO type converter, FOPID controller, Sliding mode controller, State space model

\section{Introduction}

The applications of Sliding Mode based Control (SMC) and its modeling are related to the concept of Variable Structure Systems (VSS). The theory of VSS provides a mathematical formulation to define systems that are nonlinear and time variant. This is used to define, analyze and develop control strategies. The VSS are systems whose physical structure topology is changed according to the control law defined for the particular structure. The control activity to changing the structure happens based on the current state of the system under study.

The concept of SMC is based on system states and state space. The state space analysis of each converter is done using equivalent circuits based on the switching operation. Based on the state space averaging in the nonlinear power converters, practical design criteria can be developed for the control of different converters. The control action represents the number of substructures based on the elements configured in the system. The minimum of set of substructures available in the systems depends on the control input to the system. For example, in converters, the control input represents the switching criteria based on the position ON and OFF. Proper selection of control law should be done for the selection of substructures. The control law that normally used are relay, signum function, etc. [1]

The modelling of switching DC-DC converter through the state-space approach is given in [2]. Siew-Chong Tan presented a detail discussion on the use of SM control for dcdc power converters in [3]. Here, the practical design issues of sliding-mode (SM) controllers as applied to the control of

*E-mail address: aseem@lbscek.ac.in ISSN: 1791-2377 @ 2020 School of Science, IHU. All rights reserved. doi:10.25103/|jestr.134.16 dc-dc converters are dealt. An improved pulse-widthmodulation-based sliding-mode (SM) controller for the regulation of a 2-stage dc-dc cascade boost converter is presented in [4] An experimental neural controller implementing a variable structure control (VSC) algorithm is proposed for a power factor pre regulator [5] A novel output feedback neural controller is presented in [6]. A simple unified approach to the design of fixed-frequency pulse width-modulation-based sliding-mode controllers for dc-dc converters operating in the continuous conduction mode in [7]. The discontinuous conduction mode (DCM) operation of DC-DC converters of fixed frequency PWM based SMC is discussed in [8]

The sliding mode controller details and selection of sliding surface are explained in section 2. Section 3 explains the state modelling of converters under study. Performance analysis are done in section 4 . The dynamic and transient response studies are discussed in section 5 and 6 respectively. The conclusion is presented within the segment 7 taken after by references.

\section{Sliding Mode Based Controller (Smc)}

A sliding mode-based control framework may be considered as a combination of subsystems, each with a settled structure and working in a specific locale based on the controller designed in state space. In SMC, the control design problem is to choose parameters for every structure and derive correct switching action. This uses a sliding surface that ensures to go to a desired value once the system reaches to the sliding surface. The sliding function is constructed using state variables. [10-14]. The state variables chosen in the converter is varying parameters. 
The SMC gives a strategy to design a system such that the controlled system ought to be uncaring to parameter changes and external load disturbances. This technique has two modes mainly as shown in Fig. 1:

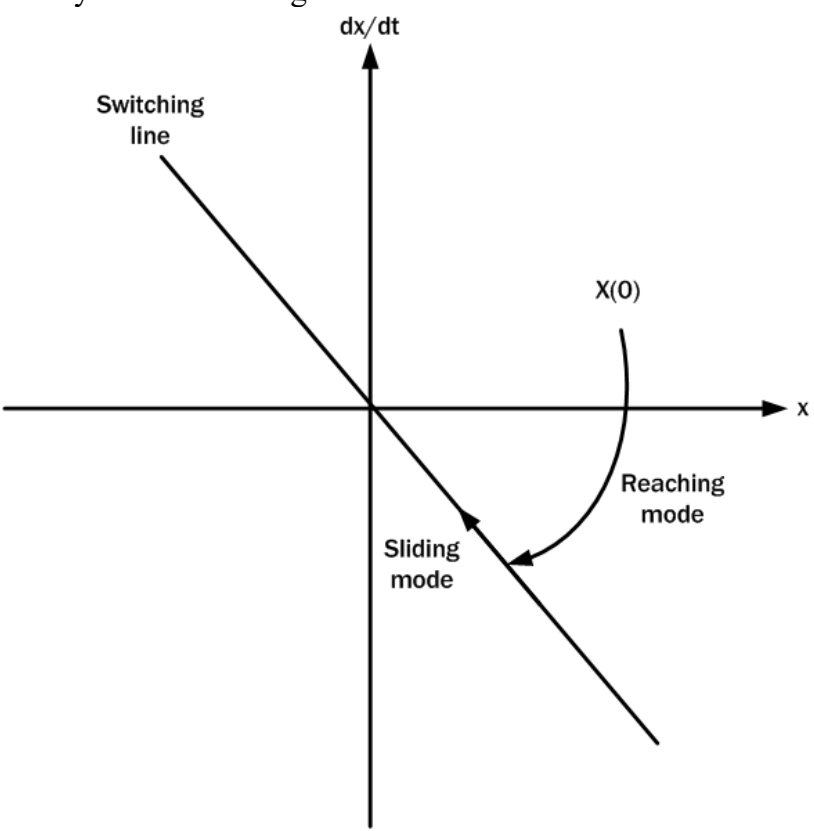

Fig. 1. Modes of SMC

(1) Reaching-mode

In this mode, the direction of trajectory moves towards the sliding surface from any beginning point. The system response is delicate to the disturbances and parameter varieties.

(2) Sliding-mode

Within the sliding mode, the trajectory moves to the origin along the switching line and the state never clears out the switching line once it gets into the line. The system here is characterized by the equation of the switching surface and is free of the system parameters.

As per the general sliding mode control principles, the sliding function is formed from state variable error that is obtained by the difference of the state variable and corresponding reference value given by the equation,

$S=x_{1}-x_{1}^{*}$

where, $x_{1}^{*}$ is the reference value set inside to the controller based on the response to be obtained.

The system trajectory is moving towards the slide surface when $S=0$ and slides over the surface.

The above mode can be realized with appropriate design of control law that satisfies Lyapunov function given by

$\mathrm{S} \dot{\mathrm{S}}<0$

Therefore,

$\dot{S}=\dot{x}_{1}-x_{1}^{*}$

\section{Modelling of Converters}

\subsection{Buck Converter}

The buck circuit generates an output lower than that of the voltage given to input terminals. Consider the circuit of buck type converter shown in Fig. 2. Depending position of SPDT switch, the systems consists of two substructures as in Fig. 3 (a) and (b). The switching variable $u$ depends on the SPDT position. Once $u=1$, inductor is connected to the input voltage $\mathrm{E}$ and when $\mathrm{u}=0$, inductor is connected to the ground. The substructures $\mathrm{a}$ and $\mathrm{b}$ are based on the circuits for $\mathrm{u}=0$ and $\mathrm{u}=1$

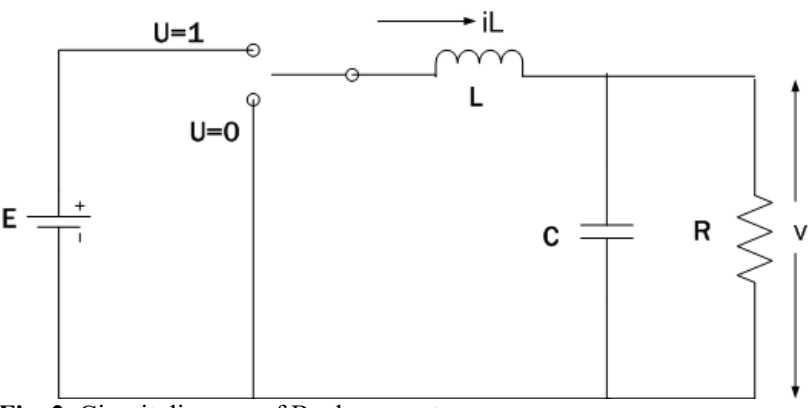

Fig. 2. Circuit diagram of Buck converter

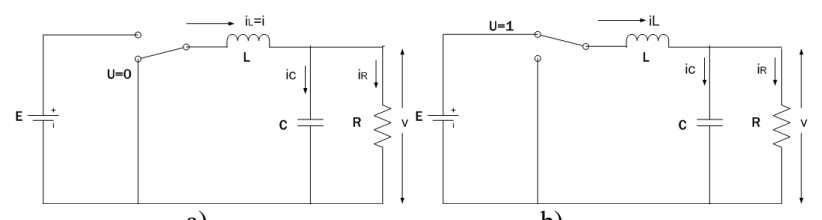

Fig. 3. Equivalent Circuit Diagrams a) When Switch OFF and b) When Switch ON

The system described by the equations as follows,

When $u=0$

$\mathrm{i}_{\mathrm{L}}=\mathrm{i}=\mathrm{i}_{\mathrm{C}}+\mathrm{i}_{\mathrm{R}}=>\mathrm{i}_{\mathrm{C}}=\mathrm{i}-\mathrm{i}_{\mathrm{R}}$

$\mathrm{C} \frac{\mathrm{d} v}{\mathrm{dt}}=\mathrm{i}-\frac{\mathrm{v}}{\mathrm{R}}$

When $u=1$

$\mathrm{L} \frac{\mathrm{di}}{\mathrm{dt}}=\mathrm{E} \cdot \mathrm{u}-v$

$\frac{\mathrm{di}}{\mathrm{dt}}=\frac{\mathrm{E} \cdot \mathrm{u}}{\mathrm{L}}-\frac{v}{\mathrm{~L}}$

On differentiating equation (1),

$\mathrm{C} \frac{\mathrm{d}^{2} v}{\mathrm{dt}^{2}}=\frac{\mathrm{di}}{\mathrm{dt}}-\frac{1}{\mathrm{R}} \frac{\mathrm{dv}}{\mathrm{dt}}$

Substitute the value of $\frac{\mathrm{di}}{\mathrm{dt}}$ in equation (3),

$\frac{\mathrm{d}^{2} v}{\mathrm{dt}^{2}}=-\frac{\mathrm{v}}{\mathrm{LC}}-\frac{1}{\mathrm{RC}} \frac{\mathrm{dv}}{\mathrm{dt}}+\frac{\mathrm{E} \cdot \mathrm{u}}{\mathrm{LC}}$

Second order system described by the following homogeneous differential equation:

$\frac{\mathrm{d}^{2} \mathrm{x}}{\mathrm{dt}^{2}}+2 \zeta \omega_{0} \frac{\mathrm{dx}}{\mathrm{dt}}+\omega_{0}^{2} x=0$

$\frac{\mathrm{d}^{2} v}{\mathrm{dt}^{2}}+\frac{1}{\mathrm{RC}} \frac{\mathrm{dv}}{\mathrm{dt}}+\frac{\mathrm{v}}{\mathrm{LC}}=\frac{\mathrm{E} \cdot \mathrm{u}}{\mathrm{LC}}$

Comparing (5) and (6),

$\omega_{0}^{2}=L C=>\omega_{0}=\frac{1}{\sqrt{L C}} ; 2 \zeta \omega_{0}=\frac{1}{R C}$

\subsubsection{Formulation of control problem}


Choose state variable as

$v=x_{1}$

$\frac{\mathrm{d} v}{\mathrm{dt}}=\dot{x}_{1}=x_{2}$

Then by equation (5),

$\dot{x}_{2}=-\omega_{0}^{2} x_{1}-2 \zeta \omega_{0} x_{2}+\omega_{0}^{2} E . u$

The phase trajectory is drawn based on the substructures. These are family of curves satisfying the dynamic properties of the system. The system state with respect to time on the phase plane is called phase trajectory. The trajectory can be drawn by the following:

Substructure 0: $\mathrm{u}=0$

Equilibrium point: $v=\frac{\mathrm{d} v}{\mathrm{dt}}=0$

Substructure 1: $\mathrm{u}=1$

Based on equation (7), there exists extra forcing term $\omega_{0}^{2} \mathrm{Eu}$. Therefore, equilibrium point: $v=E$.

Based on the control law, a sliding surface is selected that is given by

$(V *-\mathrm{v})+\tau \frac{\mathrm{d} v}{\mathrm{dt}}=0$

Substructure 0 holds for $(V *-v)+\tau \frac{\mathrm{d} v}{\mathrm{dt}}>0$

Substructure 1 holds for $(V *-\mathrm{v})+\tau \frac{\mathrm{d} v}{\mathrm{dt}}<0$

The model in state space can be developed as follows

The parameters considered for the buck converter are (1) current through the inductor $i_{L}=i$ and (2) voltage across the $\operatorname{loadv}_{\mathrm{o}}$. i.e, $i=x_{1} ; v=x_{2}$

$\mathrm{L} \frac{\mathrm{di}}{\mathrm{dt}}=\mathrm{E} \cdot \mathrm{u}-v=>\dot{\mathrm{x}}_{1}=-\frac{1}{\mathrm{~L}} \mathrm{x}_{2}+\frac{\mathrm{E}}{\mathrm{L}} \mathrm{u}$

$C \frac{\mathrm{dv}}{\mathrm{dt}}=\mathrm{i}-\frac{v}{\mathrm{R}}=>\dot{\mathrm{x}}_{2}=\frac{1}{\mathrm{C}} \mathrm{x}_{1}-\frac{1}{\mathrm{RC}} \mathrm{x}_{2}$

The state model is

$\left[\begin{array}{l}\dot{x}_{1} \\ \dot{x}_{2}\end{array}\right]=\left[\begin{array}{cc}0 & \frac{-1}{L} \\ \frac{1}{C} & \frac{-1}{R C}\end{array}\right]\left[\begin{array}{l}x_{1} \\ x_{2}\end{array}\right]+\left[\begin{array}{l}E \\ L \\ 0\end{array}\right] u$

The design values of the buck type converter is given in Table 1. The Simulink model is realized using converter mathematical model in state space with SMC as shown in Fig. 4. The buck type converter response using SMC is shown in the Fig. 5.

Table 1. Design values of buck type converter

\begin{tabular}{c|c}
\hline Parameters & Value. \\
\hline Input side Voltage (E) & $12 \mathrm{~V}$ \\
Output Voltage (v) & $5 \mathrm{~V}$ \\
Duty ratio (D) & $41.67 \%$ \\
Inductance (L) & $145.825 \mu \mathrm{H}$ \\
Capacitance (C) & $200 \mu \mathrm{F}$ \\
Resistance (R) & $5 \Omega$ \\
\hline
\end{tabular}

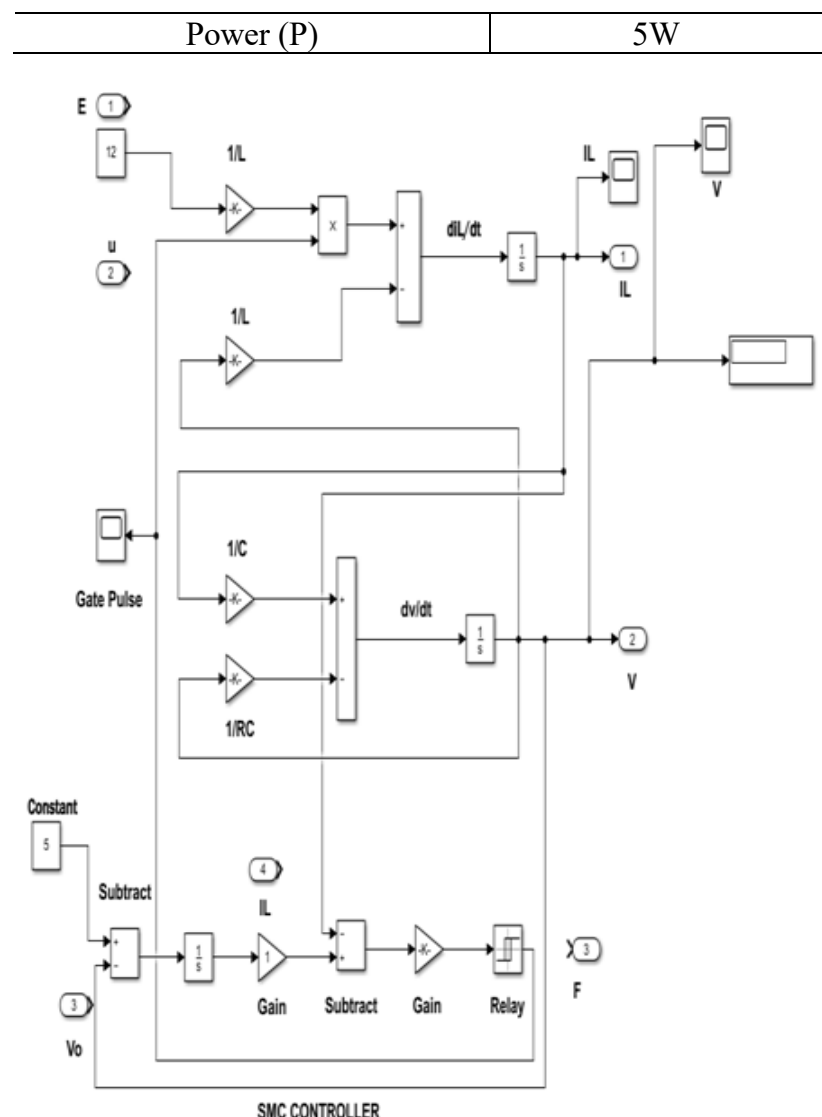

Fig. 4. Model of Buck Converter using SMC under Simulink

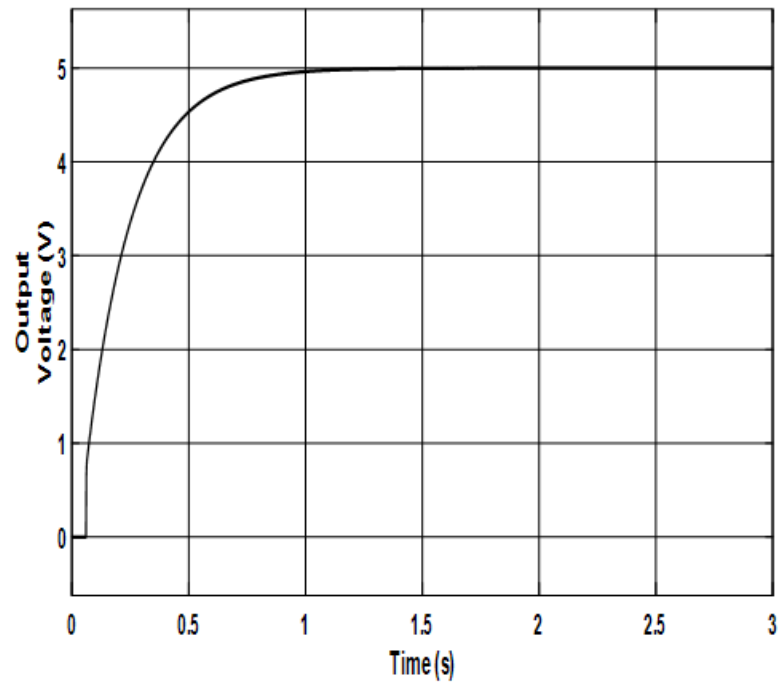

Fig. 5. Response of SMC based buck type converter

\subsection{Boost Converter}

The level of output voltage is higher than that of input side voltage in this kind of converter. The boost type converter circuit is shown in Fig. 6 and its equivalent diagrams based on the control of switch are shown in Fig. 7 (a) and (b).

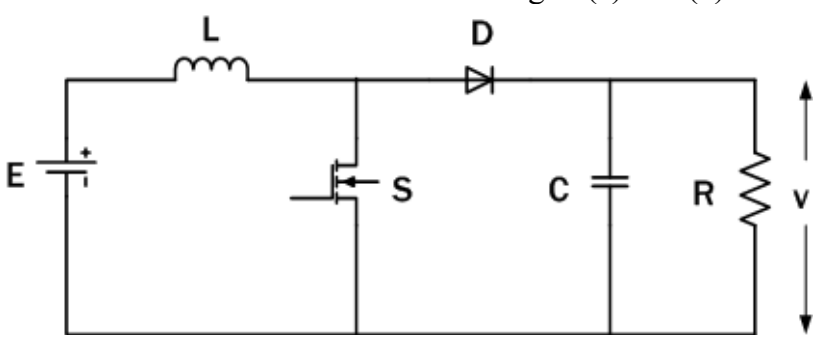

Fig. 6. Circuit Diagram of Boost Converter 


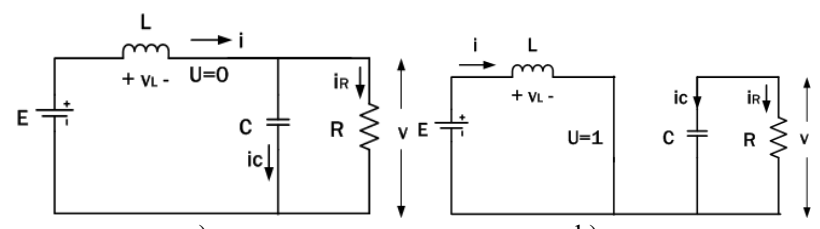

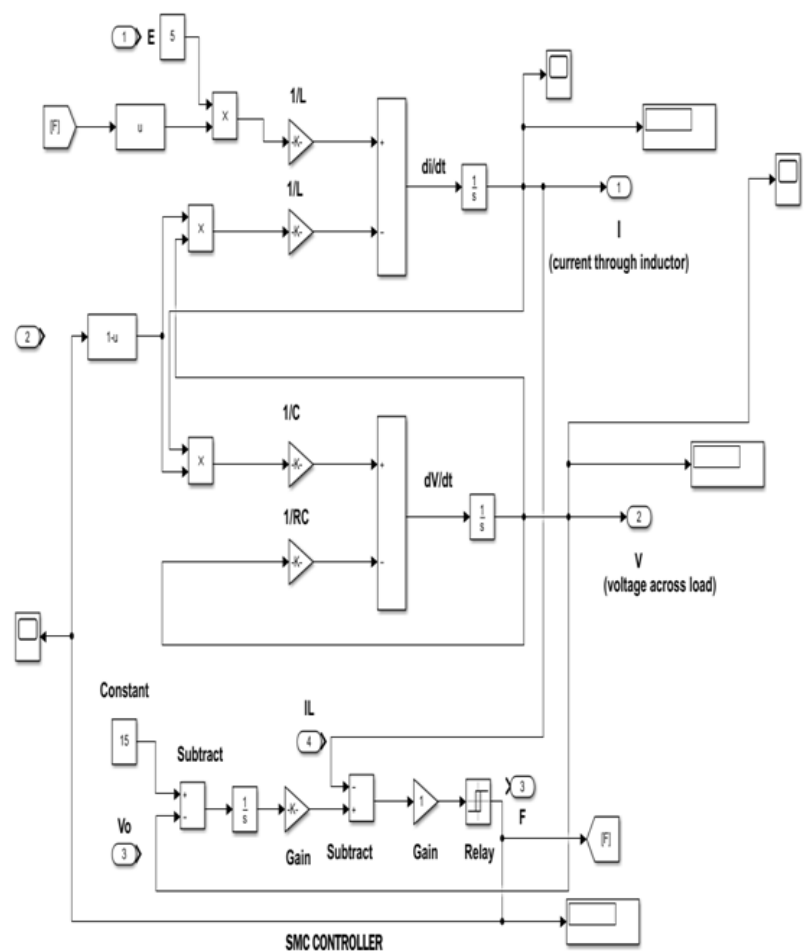

Fig. 8. Simulink model of Boost converter using SMC

$C \frac{\mathrm{dv}_{\mathrm{o}}}{\mathrm{dt}}=(1-\mathrm{u}) \mathrm{i}-\frac{v}{\mathrm{R}}$

$\frac{d v_{0}}{d t}=\frac{(1-u)}{C} i-\frac{1}{R C} v$

The state space model can be derived as follows

$\mathrm{i}_{\mathrm{C}}=\mathrm{i}-\mathrm{i}_{\mathrm{R}}$

$C \frac{\mathrm{dv}_{\mathrm{o}}}{\mathrm{dt}}=(1-\mathrm{u}) \mathrm{i}-\frac{v}{\mathrm{R}}$

$\frac{\mathrm{dv}_{\mathrm{o}}}{\mathrm{dt}}=\frac{(1-\mathrm{u})}{\mathrm{C}} \mathrm{i}-\frac{1}{\mathrm{RC}} \mathrm{v}$

The converter model in state space can be written by taking $\mathrm{i}=x_{1}$ and $v=x_{2}$

$\left[\begin{array}{l}\dot{x}_{1} \\ \dot{x}_{2}\end{array}\right]=\left[\begin{array}{cc}0 & \frac{-(1-u)}{L} \\ \frac{(1-u)}{C} & \frac{-1}{R C}\end{array}\right]\left[\begin{array}{l}x_{1} \\ x_{2}\end{array}\right]+\left[\begin{array}{l}\frac{E}{L} \\ 0\end{array}\right]$

The Simulink model realized using buck converter model in state space using SMC and is given in Fig. 8. The design values of the boost dc to dc converter is listed in Table 2 . The boost type converter response with SMC is shown in the Fig. 9.

Table 2. Design values of boost type converter

\begin{tabular}{c|c}
\hline Parameter. & Value. \\
\hline Input Voltage (E) & $5 \mathrm{~V}$ \\
Output Voltage (v) & $15 \mathrm{~V}$ \\
Duty ratio (D) & $66.67 \%$ \\
Inductance (L) & $150 \mu \mathrm{H}$ \\
Capacitance (C) & $220 \mu \mathrm{F}$ \\
Resistance (R) & $30 \Omega$ \\
Power (P) & $7.5 \mathrm{~W}$ \\
\hline
\end{tabular}

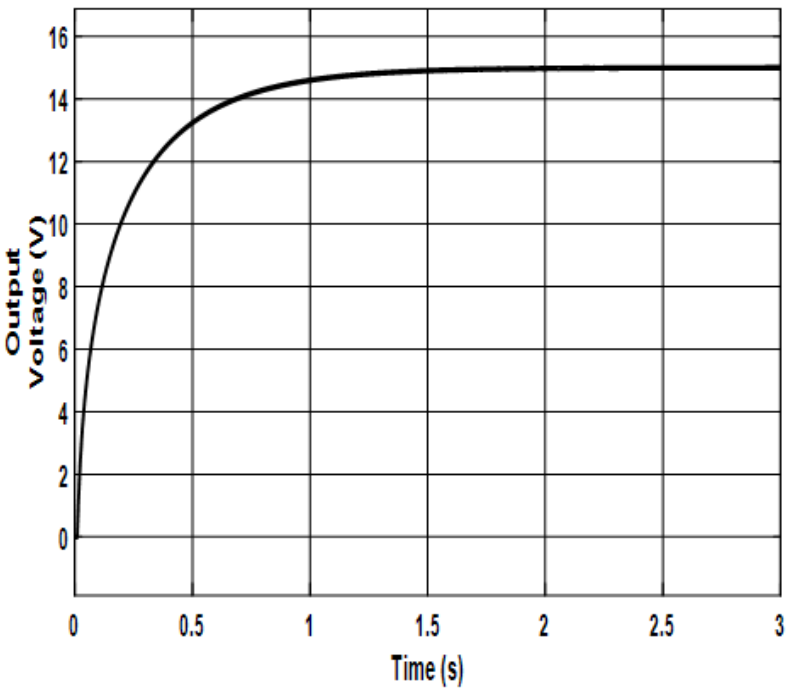

Fig. 9. Response of SMC based boost type converter

\subsection{Buck-Boost type Converter}

This converter delivers an output voltage level which can be controlled over and underneath the level of the input voltage based on the variation of the duty cycle. The converter circuit schematic is shown in Fig. 10 and the equivalent circuit diagrams are shown in Fig. 11 (a) and (b).

$\mathrm{S}$

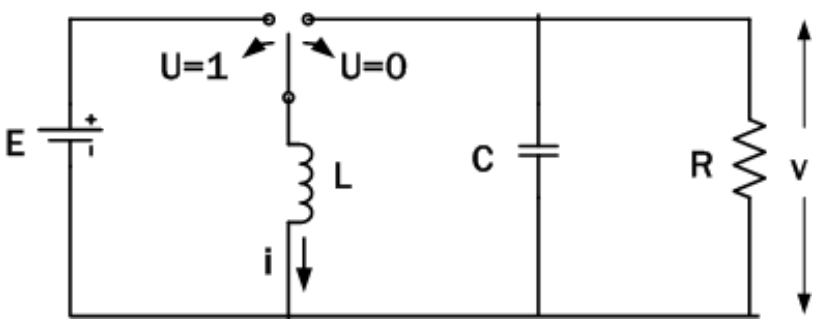

Fig. 10. Circuit Diagram of Buck-boost type converter 


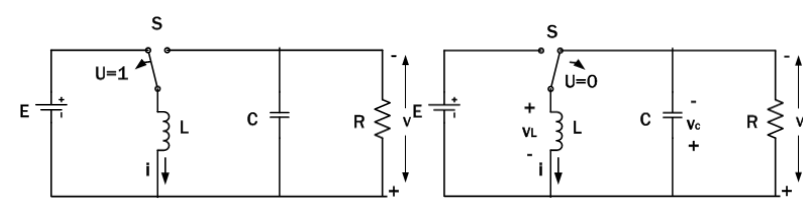

a)

b)

Fig. 11. Equivalent Circuit Diagrams a) When Switch OFF and b) When Switch ON

During the switch $\mathrm{S}$ is $\mathrm{ON}(\mathrm{u}=1)$, voltage across inductor is given by,

$\mathrm{v}_{\mathrm{L}}=\mathrm{E}$

$\Rightarrow \frac{\mathrm{di}}{\mathrm{dt}}=\frac{E}{L}$

The current flowing through the capacitor is given by,

$\mathrm{i}_{\mathrm{C}}=\mathrm{C} \frac{\mathrm{dv}}{\mathrm{dt}}=-\frac{\mathrm{v}}{\mathrm{R}}$

$\Rightarrow \frac{\mathrm{dv}}{\mathrm{dt}}=-\frac{\mathrm{v}}{\mathrm{RC}}$

When the switch is OFF $(u=0)$, the current through inductor and capacitor voltage are given by,

$\frac{\mathrm{di}}{\mathrm{dt}}=\frac{v}{L}$

$\frac{\mathrm{dv}}{\mathrm{dt}}=-\frac{\mathrm{i}}{\mathrm{C}}-\frac{\mathrm{v}}{\mathrm{RC}}$

Let the control vector ' $\mathrm{u}$ ' and the state variables are $x_{1}=$ $i$ and $x_{2}=v$. The state model is

$\left[\begin{array}{c}\dot{\mathrm{x}}_{1} \\ \dot{\mathrm{x}}_{2}\end{array}\right]=\left[\begin{array}{cc}0 & \frac{-(1-\mathrm{u})}{\mathrm{L}} \\ \frac{-(1-\mathrm{u})}{\mathrm{C}} & \frac{-1}{\mathrm{RC}}\end{array}\right]\left[\begin{array}{l}\mathrm{x}_{1} \\ \mathrm{x}_{2}\end{array}\right]+\left[\begin{array}{l}\mathrm{E} \\ \frac{\mathrm{L}}{0}\end{array}\right] \mathrm{u}$

The design values of the buck-boost type converter is given in Table 3. The Simulink model realized using converter model in state space and with SMC is given in Fig.12. The response of the buck -boost type converter using SMC is illustrated in the Fig. 13.

Table 3. Design parameters of buck-boost converter

\begin{tabular}{c|c}
\hline Parameter. & Value. \\
\hline Input side Voltage (E) & $12 \mathrm{~V}$ \\
\hline Output side Voltage $\left(\mathrm{v}_{\mathrm{O}}\right)$ & $-4 \mathrm{~V}$ \\
\hline Duty ratio (D) & $25 \%$ \\
\hline Inductance (L) & $150 \mu \mathrm{H}$ \\
\hline Capacitance (C) & $220 \mu \mathrm{F}$ \\
\hline Resistance (R) & $3.2 \Omega$ \\
\hline Power (P) & $5 \mathrm{~W}$ \\
\hline
\end{tabular}

\subsection{Dual- Input and Single-Output (DISO) type} converter

The dual-input and single-output converter consists of stepdown converters with high ratio of the input voltages connected to a single output. In accordance with the switching algorithm of switches $\mathrm{S}_{1}$ and $\mathrm{S}_{2}$, converter operating modes are defined and hence the converter can draw power from input from the input sources simultaneously or individually.
The DISO converter is as shown in Fig. 14 and the four modes of operation is given in Fig. 15.

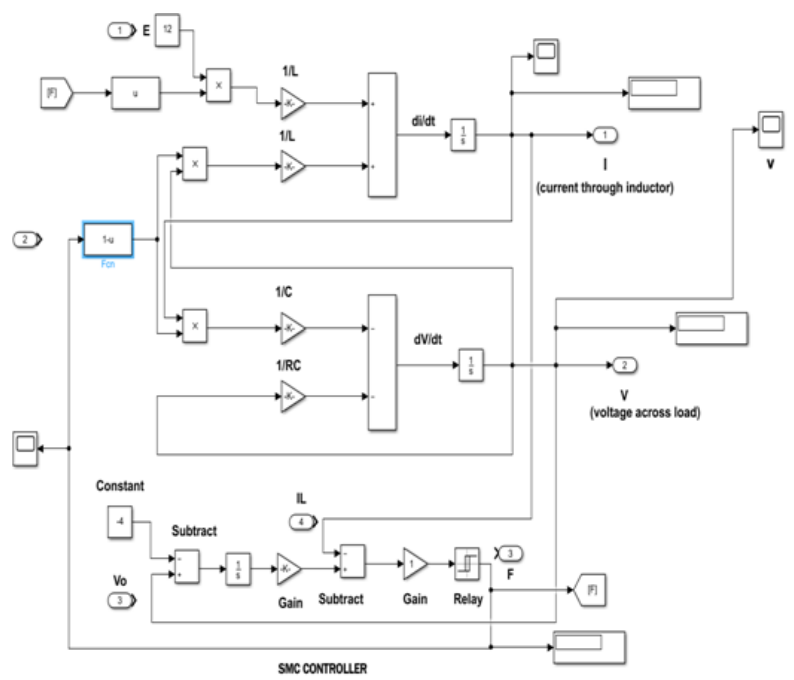

Fig. 12. Simulink model of Buck-boost type converter

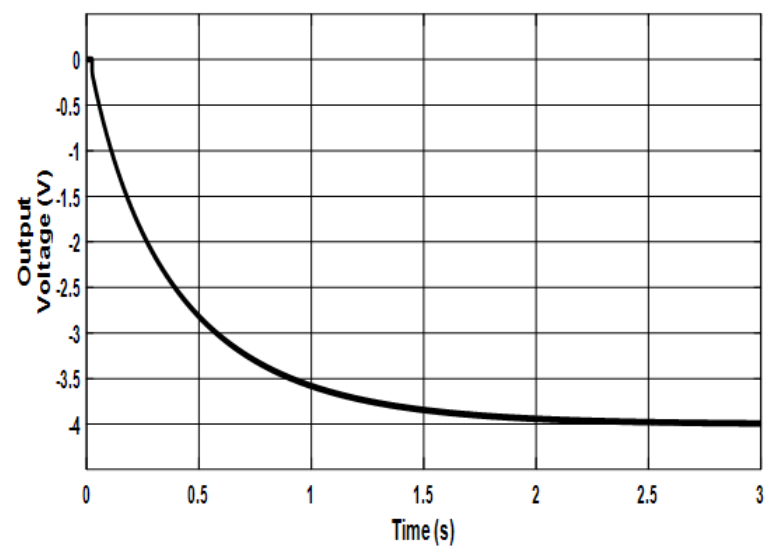

Fig. 13. Response of Buck-boost converter

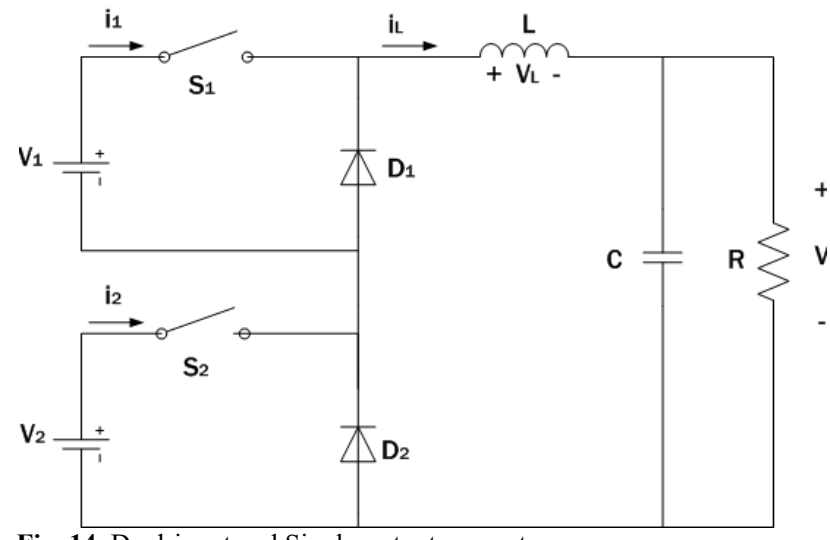

Fig. 14. Dual-input and Single-output converter

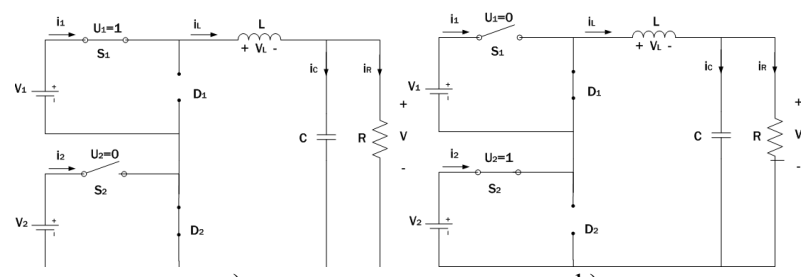

a)

b) 


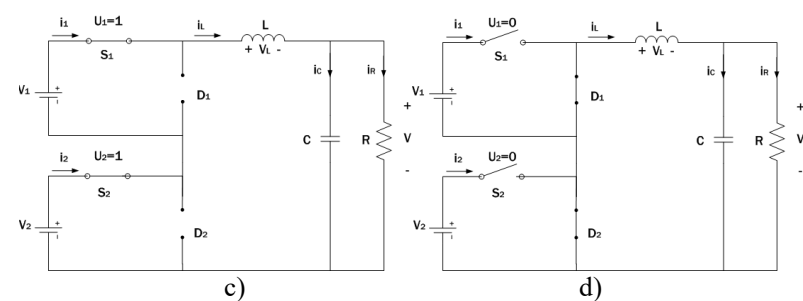

Fig. 15. Different modes of operation of dual input and single output converter

The modes of operations are:

Mode $1\left(S_{1}\right.$ is $O N$ and $S_{2}$ is $\left.O F F\right)$ :

When the switch $\mathrm{S}_{1}$ is on, the diode $\mathrm{D}_{1}$ become reverse biased. Also, diode $\mathrm{D}_{2}$ starts conduction and inductor current $\mathrm{i}_{\mathrm{L}}$ flows. The voltage source $\mathrm{V}_{1}$ delivers energy to the both inductor $\mathrm{L}$ and load resistance $\mathrm{R}$. The inductor voltage is given by,

$\mathrm{v}_{\mathrm{L}}=\mathrm{V}_{1}-\mathrm{v} \Rightarrow \mathrm{L} \frac{\mathrm{di}_{\mathrm{L}}}{\mathrm{dt}}=\mathrm{V}_{1} \mathrm{u}_{1}-\mathrm{v}$

$\frac{\mathrm{di}_{\mathrm{L}}}{\mathrm{dt}}=\frac{\mathrm{V}_{1}}{\mathrm{~L}} \mathrm{u}_{1}-\frac{\mathrm{v}}{\mathrm{L}}$

\section{Mode $2\left(S_{1}\right.$ is $O F F$ and $S_{2}$ is $\left.O N\right)$ :}

Here the diode $\mathrm{D}_{1}$ starts conduction whereas diode $\mathrm{D}_{2}$ become reverse biased. The load and inductor receive energy from supply $\mathrm{V}_{2}$. The voltage across inductor in this mode is given by,

$\mathrm{v}_{\mathrm{L}}=\mathrm{V}_{2}-\mathrm{v}$

$\frac{\mathrm{di}_{\mathrm{L}}}{\mathrm{dt}}=\frac{\mathrm{V}_{2}}{\mathrm{~L}} \mathrm{u}_{2}-\frac{\mathrm{v}}{\mathrm{L}}$

\section{Mode 3 (Both $S_{1}$ and $S_{2}$ are in $\mathbf{O F F ) : ~}$}

In this mode, both $\mathrm{D}_{1}$ and $\mathrm{D}_{2}$ provides the way to flow inductor current $\mathrm{i}_{\mathrm{L}}$ as both the switches are OFF. The stored energy in the inductor $\mathrm{L}$ feeds the load connected. The inductor voltage $\mathrm{v}_{\mathrm{L}}$ is given by,

$$
\begin{aligned}
& \mathrm{v}_{\mathrm{L}}=-\mathrm{v} \\
& \frac{\mathrm{di} \mathrm{L}}{\mathrm{dt}}=-\frac{\mathrm{v}}{\mathrm{L}}
\end{aligned}
$$

Mode 4 (Both $S_{1}$ and $S_{2}$ are $O N$ ):

In this mode, both switches $\mathrm{S} 1$ and $\mathrm{S}_{2}$ are turned $\mathrm{ON}$. Both diodes $\mathrm{D}_{1}$ and $\mathrm{D}_{2}$ are turned OFF. Two sources are series connected. Hence the inductor is energized and the voltage across inductor is given by,

$\frac{\mathrm{di}_{\mathrm{L}}}{\mathrm{dt}}=\frac{\mathrm{v}_{1}}{\mathrm{~L}} \mathrm{u}_{1}+\frac{\mathrm{v}_{2}}{\mathrm{~L}} \mathrm{u}_{2}-\frac{\mathrm{v}}{\mathrm{L}}$

The current flowing through the capacitor for all modes of operation is given by,

$\mathrm{i}_{\mathrm{C}}=\mathrm{i}_{\mathrm{L}}-\mathrm{i}_{0}$

$\frac{\mathrm{dv}_{0}}{\mathrm{dt}}=\frac{\mathrm{i}}{\mathrm{C}}-\frac{v}{\mathrm{RC}}$

Using equations (4) and (5), the state space analysis done by choosing $x_{1}=i_{L}$ and $x_{2}=v$,

$\dot{\mathrm{x}}_{1}=-\frac{\mathrm{x}_{2}}{\mathrm{~L}}+\frac{\mathrm{V}_{1}}{\mathrm{~L}} \mathrm{u}_{1}+\frac{\mathrm{V}_{2}}{\mathrm{~L}} \mathrm{u}_{2}$
$\dot{\mathrm{x}}_{2}=\frac{\mathrm{x}_{1}}{\mathrm{C}}-\frac{\mathrm{x}_{2}}{\mathrm{RC}}$

$\left[\begin{array}{c}\dot{\mathrm{x}}_{1} \\ \dot{\mathrm{x}}_{2}\end{array}\right]=\left[\begin{array}{cc}0 & -\frac{1}{\mathrm{~L}} \\ \frac{1}{\mathrm{C}} & \frac{-1}{\mathrm{RC}}\end{array}\right]\left[\begin{array}{l}\mathrm{x}_{1} \\ \mathrm{x}_{2}\end{array}\right]+\left[\begin{array}{c}\frac{V_{1}}{\mathrm{~L}} \\ 0\end{array}\right] u_{1}+\left[\begin{array}{c}\frac{V_{2}}{\mathrm{~L}} \\ 0\end{array}\right] u_{2}$

For DISO converter, two SMC controllers are used to realize the control system. The Simulink model and corresponding waveforms are shown in Fig. 16 and Fig. 17.

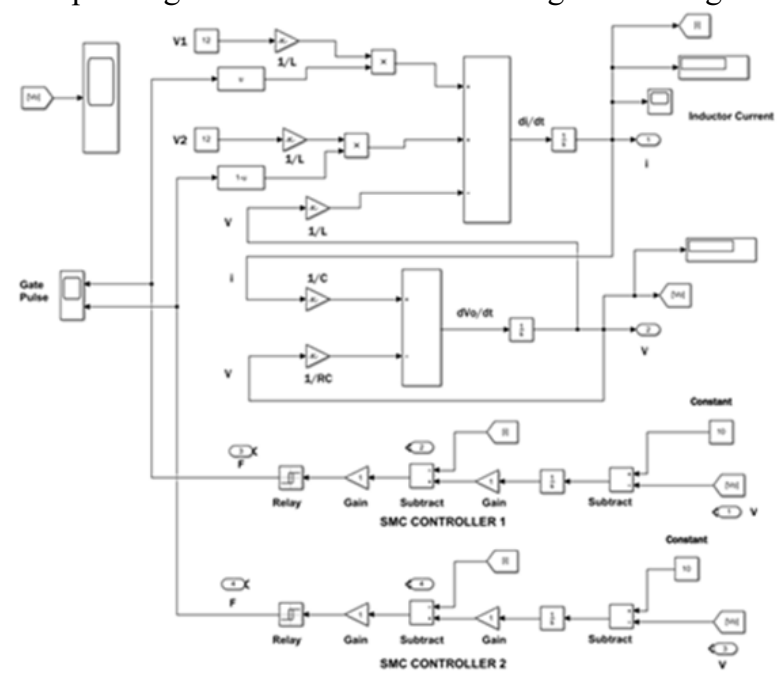

Fig. 16. Simulink model of DISO converter

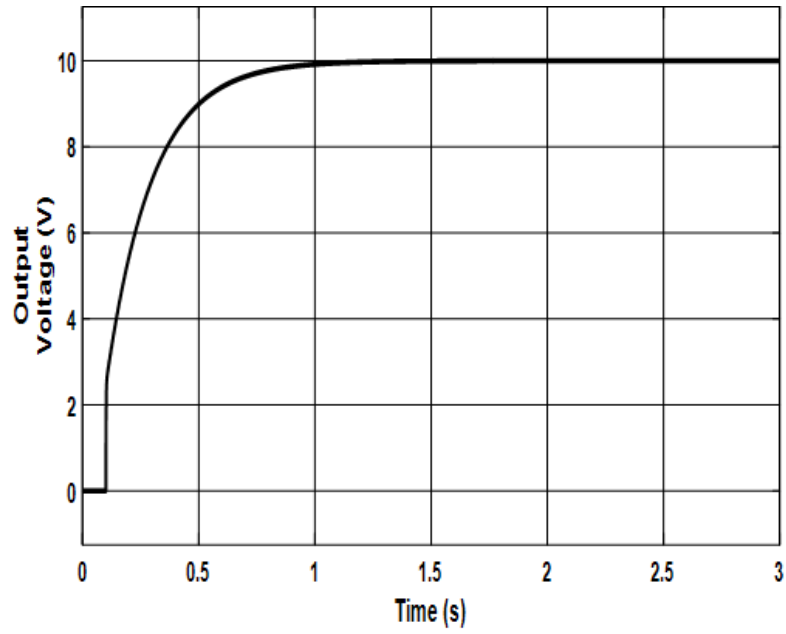

Fig. 17. Output voltage waveform of DISO Converter

The design values of the DISO converter is given in Table 4. The Simulink model realized using buck converter model in state space and SMC is shown in Fig.16 The output response of the buck type converter with SMC is shown in Fig. 17.

Table 4. Design parameters of DISO Converter

\begin{tabular}{c|c}
\hline Parameter & Value \\
\hline Input Voltages $\left(\mathrm{V}_{1}\right.$ and $\left.\mathrm{V}_{2}\right)$ & $12 \mathrm{~V}, 12 \mathrm{~V}$ \\
Output Voltage $(v)$ & $10 \mathrm{~V}$ \\
Duty ratio (D) & $41.67 \%$ \\
Inductance (L) & $145.825 \mu \mathrm{H}$ \\
Capacitance (C) & $200 \mu \mathrm{F}$ \\
Resistance (R) & $5 \Omega$ \\
Power (P) & $5 \mathrm{~W}$ \\
\hline
\end{tabular}




\section{Comparitive Analysis of PID, Fractional PID and SM Type Controllers}

For the simulation analysing of DC/DC converters, some assumptions are taken. Here all the components in the circuit are assumed as no power loss. Switching frequency is taken as constant. The circuit is operating in steady state and inductor current is assumed to be continuous (always positive). The capacitor is assumed to be very large so that the output voltage is held at constant at voltage

\subsection{Buck Converter}

The usefulness of buck type converter using ordinary PID, FOPID and SMC controller are compared in terms of domain specifications. The output voltages are regulated at $5 \mathrm{~V}$ in all controllers. The rise time with SMC is much larger with respect to PID and FOPID controllers. The overshoot and undershoot are very lower value in SMC. The ripple voltage is very less with SMC. The settling time is a larger value with SMC compared with other controllers as listed in Table 5. The comparative response analysis of converter based on three controller are given in Fig. 18

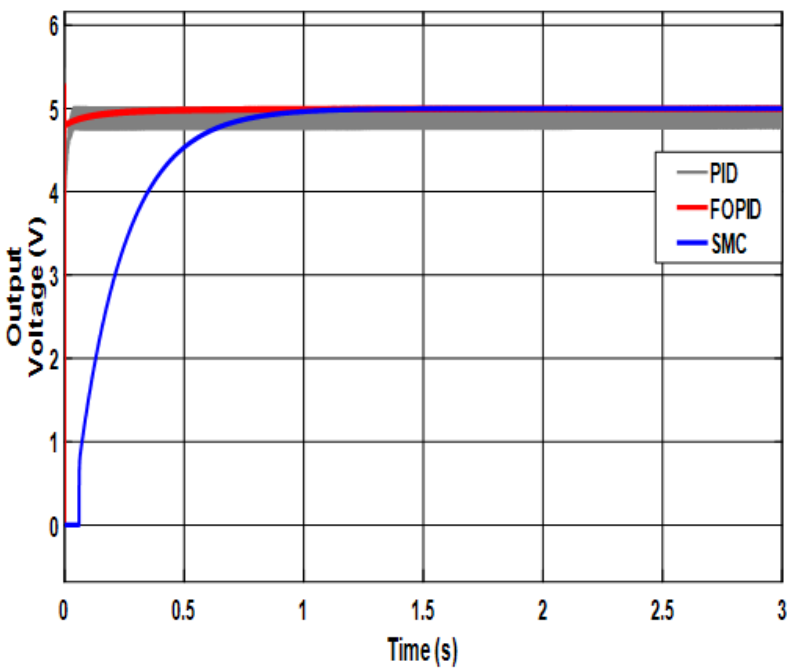

Fig. 18. Output response of Buck type topology using PID, FOPID and $\mathrm{SMC}$

Table 5. The comparitive analysis of response of buck type converter with ordinary PID, FOPID \& SMC

\begin{tabular}{c|c|c|c|c|c|c|c}
\hline $\begin{array}{c}\text { Controller } \\
\text { Type }\end{array}$ & $\begin{array}{c}\text { Vd- } \\
(\mathbf{V})\end{array}$ & Vo- (V) & $\begin{array}{c}\text { Rise-Time } \\
(\boldsymbol{\mu s})\end{array}$ & $\begin{array}{c}\text { Slew-rate } \\
(\mathbf{/ m s})\end{array}$ & $\begin{array}{c}\text { Over-shoot } \\
\mathbf{\%}\end{array}$ & $\begin{array}{c}\text { Under-Shoot } \\
\mathbf{\%}\end{array}$ & $\begin{array}{c}\text { Settling-time } \\
(\mathbf{m s})\end{array}$ \\
\hline PID & 12 & 5 & 146.535 & 23.604 & 15.82 & 28.512 & 1.55 \\
FOPID & 12 & 5 & 211.188 & 17.393 & 6.322 & 18.522 & 1.102 \\
SMC & 12 & 5 & 417.835 & $9.480 / \mathbf{s}$ & 0.500 & 2.055 & 0.7 \\
\hline
\end{tabular}

\subsection{Boost Converter}

The execution of boost type converter using ordinary PID, FOPID and SMC controllers are compared using time domain specifications. The risetime with SMC is larger value with respect to PID and FOPID controllers. The overshoot and undershoot are very lower value in SMC. The ripple voltage is very less with SMC. The settling time is a larger value with SMC controller compared with other controllers as listed in Table 6 . The comparative analysis of response of converter based on three controller are given in Fig. 19.

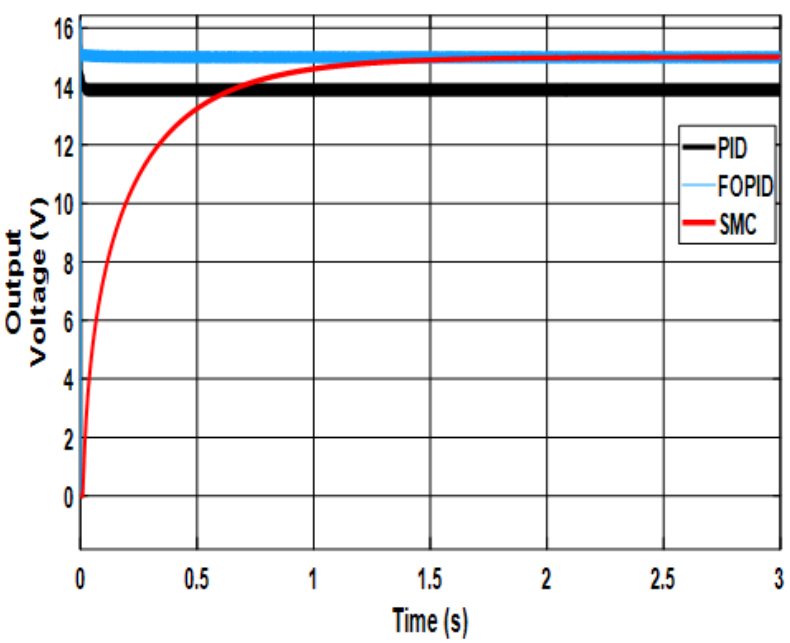

Fig. 19. Response of Boost type converter using PID, FOPID and SMC

Table 6. The comparitive analysis of response of boost type converter with PID, FOPID \& SMC

\begin{tabular}{c|c|c|c|c|c|c|c}
\hline $\begin{array}{c}\text { Controller } \\
\text { type }\end{array}$ & Vd-(V) & Vo-(V) & $\begin{array}{c}\text { Rise-Time } \\
(\mathbf{m s})\end{array}$ & $\begin{array}{c}\text { Slew-rate } \\
(\mathbf{m s})\end{array}$ & $\begin{array}{c}\text { Over-shoot } \\
\mathbf{\%}\end{array}$ & Under-Shoot \% & $\begin{array}{c}\text { Settling-time } \\
(\mathbf{m s})\end{array}$ \\
\hline PID & 5 & 14.5 & 0.12 & 19.154 & 14.368 & 1.464 & 1.4 \\
FOPID & 5 & 15 & 0.11 & 20.062 & 8.152 & 0.919 & 1.12 \\
SMC & 5 & 15 & 0.35 & 11 & 2.5 & 0.3 & 1.1 \\
\hline
\end{tabular}

\subsection{Buck-Boost type Converter}

The performance of buck-boost type topology using ordinary PID, FOPID and SMC controllers are compared using time domain specifications. The rise time with SMC is larger value with respect to PID and FOPID controllers. The overshoot and undershoot are very lower value in SMC. The ripple voltage is very less with SMC. The settling time is a larger value with SMC controller compared with other controllers as enumerated in Table 7. The comparative analysis of responses of converters based on three controllers are given in Fig. 20.

Table 7. The comparitive analysis of response of buck-boost type converter with PID, FOPID \& SMC

\begin{tabular}{c|c|c|c|c|c|c|c}
\hline $\begin{array}{c}\text { Controller } \\
\text { type }\end{array}$ & Vd-(V) & Vo-(V) & $\begin{array}{c}\text { Rise-Time } \\
(/ \mathbf{m s})\end{array}$ & $\begin{array}{c}\text { Slew-rate } \\
(/ \mathbf{m s})\end{array}$ & $\begin{array}{c}\text { Over-shoot } \\
\%\end{array}$ & Under-Shoot \% & $\begin{array}{c}\text { Settling-time } \\
(\mathbf{m s})\end{array}$ \\
\hline PID & 12 & -4 & 0.021 & -15.68 & 15.187 & 1.800 & 2.4
\end{tabular}




\begin{tabular}{c|c|c|c|c|c|c|c} 
FOPID & 12 & -4 & 0.044 & -4.690 & 9.555 & 1.193 & 1.8 \\
SMC & 12 & -4 & 0.4 & 0 & 0 & 0 & 1.5 \\
\hline
\end{tabular}

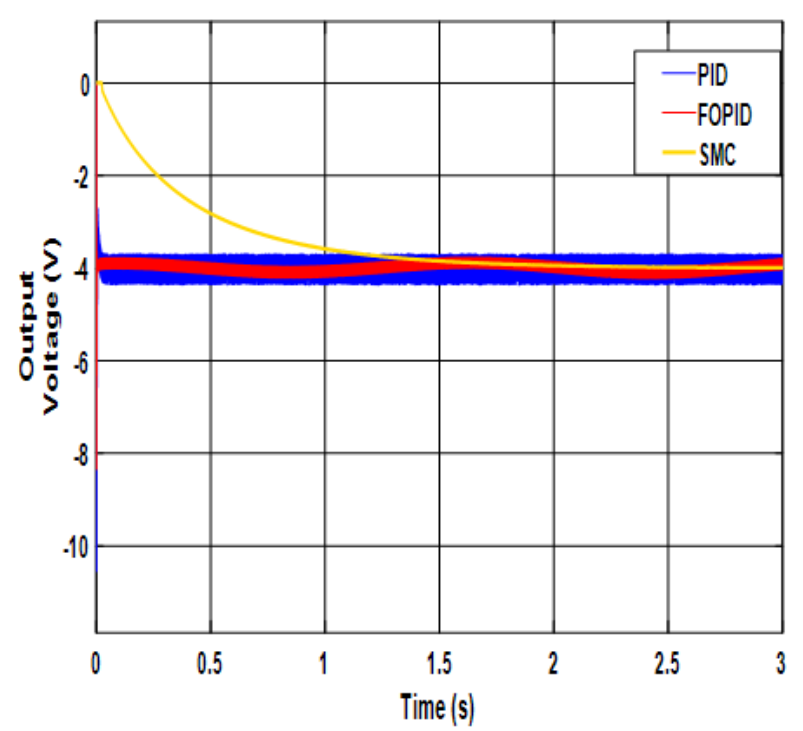

Fig. 20. Response of Buck-boost topology using PID, FOPID and SMC

\subsection{DISO Converter}

The introduction of DISO type converter using ordinary PID, FOPID and SMC control systems are compared in terms of domain specifications. The output voltages are regulated at $12 \mathrm{~V}$ in all controllers. The rise time with $\mathrm{SMC}$ is larger value with respect to PID and FOPID controllers. The overshoot and undershoot are very lower value in SMC controller. The settling time is a larger value with SMC compared with other controllers as listed in Table 8. The comparative analysis of responses of converters based on three type controllers are given in Fig. 21

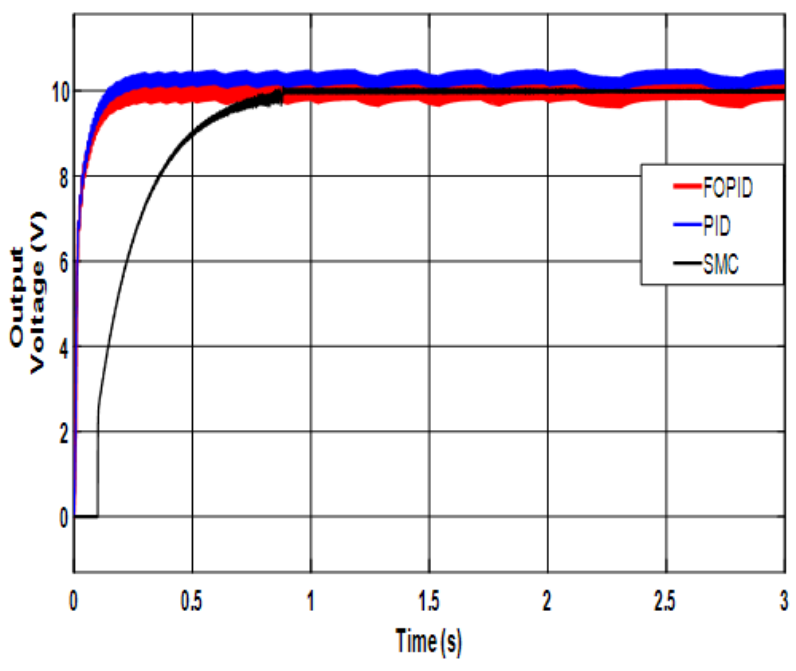

Fig. 22. Step response of buck converter using PID, FOPID and SMC

Table 8. The comparitive analysis of response of of DISO type converter with PID, FOPID \& SMC

\begin{tabular}{c|c|c|c|c|c|c|c|c}
\hline $\begin{array}{c}\text { Controller } \\
\text { type }\end{array}$ & V1-(V) & V2-(V) & Vo-(V) & $\begin{array}{c}\text { Rise-Time } \\
(\mathbf{m s})\end{array}$ & $\begin{array}{c}\text { Slew-rate } \\
(/ \mathbf{s})\end{array}$ & $\begin{array}{c}\text { Over-shoot } \\
\text { \% }\end{array}$ & $\begin{array}{c}\text { Under- } \\
\text { Shoot } \\
\text { \%o }\end{array}$ & $\begin{array}{c}\text { Settling- } \\
\text { Time }\end{array}$ \\
\hline PID & 12 & 12 & 9.9 & 0.2 & 129.328 & 3.058 & 4.794 & 1.32 \\
FOPID & 12 & 12 & 10 & 0.05 & 107.297 & 2.005 & 4.577 & 1.29 \\
SMC & 12 & 12 & 10 & 0.4 & 20.106 & 0.505 & 3.842 & 0.7 \\
\hline
\end{tabular}

\section{Dynamic Performance of PID, Fractional PID and SM Type Controllers}

The dynamic performance of the controllers is examined under the step variation of the input voltage. The various converters are controlled under the step change in voltage and corresponding time domain performance specifications are tabulated. All the time domain specifications are measured for the period after the step change in input to analyse how fast the controller regains the steady state after disturbance. The step response of the buck converter is shown in Fig. 22. The performance can be evaluated from the Table 9. In case of buck converter, a step change in input voltage from $12 \mathrm{~V}$ to $15 \mathrm{~V}$ applied. The corresponding response is plotted. Al the three controllers are able to track the changes input, but the smooth transition is offered by SM controller only. The response with the SM controller has lesser settling time and pre-shoot values. The overshot is considerably reduced with SM controller to $0.5 \%$ compared with PID and FOPID controllers. Ripple voltage is $0.003 \mathrm{~V}$ with $\mathrm{SM}$ controller which negligible value compared to other controllers.

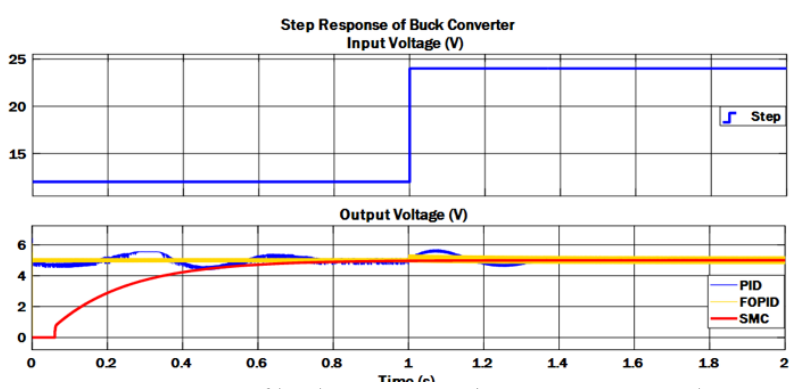

Fig. 22. Step response of buck converter using PID, FOPID and SMC

Table 9. The comparitive analysis of step response of of buck type converter with PID, FOPID \& SMC

\begin{tabular}{|c|c|c|c|c|c|c|c|}
\hline Controller & Rise Time $(\mu \mathrm{s})$ & $\begin{array}{c}\text { Slew rate } \\
(/ \mathrm{ms})\end{array}$ & $\begin{array}{l}\text { Pre-shoot } \\
(\%)\end{array}$ & $\begin{array}{l}\text { Over-shoot } \\
(\%)\end{array}$ & Undershoot (\%) & $\underset{\text { (s) }}{\text { Settling Time }}$ & $\begin{array}{c}\text { Ripple } \\
\text { voltage } \\
\text { (V) }\end{array}$ \\
\hline PID & 159.326 & 23.888 & 6.081 & 36.429 & 6.873 & 0.9 & 0.5 \\
\hline FOPID & 110.424 & 32.211 & 11.644 & 20.342 & 0.064 & 0.6 & 0.2 \\
\hline SMC & 98.326 & 30.942 & 0.505 & 0.505 & - & 0.2 & 0.003 \\
\hline
\end{tabular}


A step change in input voltage from $5 \mathrm{~V}$ to $8 \mathrm{~V}$ is applied to boost converter and the response is plotted as shown in Fig. 23. The performance parameters are tabulated in Table 10. The overshoot is $1.42 \%$ with SM controller. The value of overshoot and ripple voltage are very less with SM controller.

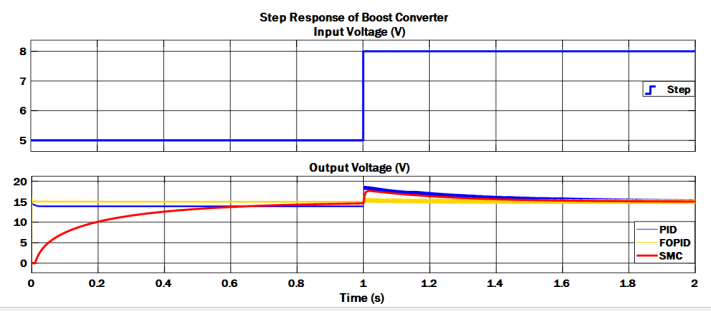

Fig. 23. Step response of boos converter using PID, FOPID and SMC

Table 10. The comparitive analysis of step response of of boost type converter with PID, FOPID \& SMC

\begin{tabular}{|c|c|c|c|c|c|c|c|}
\hline Controller & Rise Time $(\mu \mathrm{s})$ & $\begin{array}{c}\text { Slew rate } \\
(/ \mathrm{ms})\end{array}$ & Pre-shoot (\%) & Over-shoot (\%) & Undershoot (\%) & Settling Time (s) & $\begin{array}{c}\text { Ripple } \\
\text { voltage } \\
\text { (V) }\end{array}$ \\
\hline PID & 589.076 & 19.444 & 0.625 & 10.609 & 0.262 & 0.8 & 1 \\
\hline FOPID & 596.196 & 20.032 & 0.543 & 8.152 & 0.975 & 0.7 & 0.5 \\
\hline SMC & 626.198 & 24.512 & 0.505 & 1.423 & - & 0.4 & 0.004 \\
\hline
\end{tabular}

The step response of buck-boost converter and DISO converters are shown in the Fig. 24 and Fig. 25 respectively. The various time domain specifications are tabulated in the Tables 11 and 12 respectively. Overshoot and ripple voltages are drastically reduced with SM controller in these two converters. SM control has a smaller overshoot and zero steady state error than other controllers. PID and FOPID shows poor large-signal transient response due to the oscillatory nature of the output voltage. From the results, it is shown that the output of converter is not affected by the input voltage variation in case of SM control whereas the performance of converter with PID and FOPID degrades with a large overshoot and larger steady state error. This demonstrates the advantage SM controller over PID and FOPID for providing faster transient response for a wide operating range. The SM control method shows better dynamics for changes in input voltage and load. It can be seen that the SM control method can well regulate the output voltage even in large range of line variation.

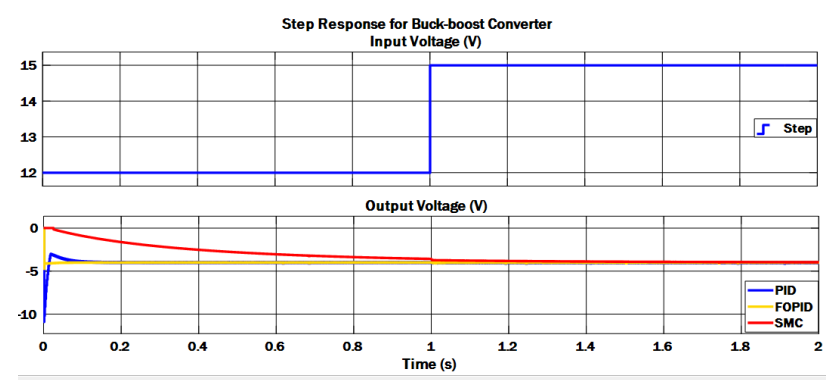

Fig. 24. Step response of buck-boost converter using PID, FOPID and SMC

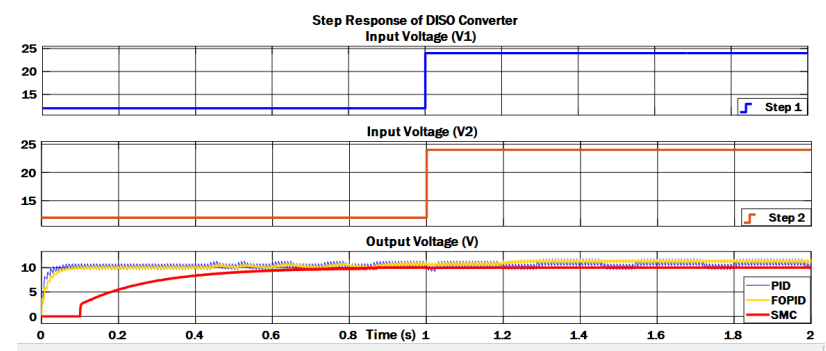

Fig. 25. Step response of DISO converter using PID, FOPID and SMC

Table 11. The comparitive analysis of step response of of buck-boost converter with PID, FOPID \& SMC

\begin{tabular}{|c|c|c|c|c|c|c|c|}
\hline Controller & $\begin{array}{c}\text { Fall } \\
\text { Time }(\mu s)\end{array}$ & $\begin{array}{l}\text { Slew rate } \\
(/ \mathbf{m s})\end{array}$ & $\begin{array}{l}\text { Pre-shoot } \\
(\%)\end{array}$ & $\begin{array}{c}\text { Over-shoot } \\
(\%)\end{array}$ & Undershoot (\%) & $\begin{array}{l}\text { Settling Time } \\
(\mathrm{ms})\end{array}$ & $\begin{array}{c}\text { Ripple } \\
\text { voltage } \\
\text { (V) }\end{array}$ \\
\hline PID & 41.473 & 54.699 & 36.728 & 8.330 & 67.508 & 0.8 & 0.84 \\
\hline FOPID & 175.013 & 18.236 & 0.595 & 1.491 & 18.452 & 0.55 & 0.43 \\
\hline SMC & $920.304 \mathrm{~ms}$ & 3.416 & 0.500 & 0.505 & - & 0.4 & 0.006 \\
\hline
\end{tabular}

Table 12. The comparitive analysis of step response of of DISO converter with PID, FOPID \& SMC

\begin{tabular}{|c|c|c|c|c|c|c|c|}
\hline Controller & $\begin{array}{l}\text { Rise Time } \\
\quad(\mathrm{ms})\end{array}$ & $\begin{array}{c}\text { Slew rate } \\
(/ / \mathbf{s})\end{array}$ & $\begin{array}{l}\text { Pre-shoot } \\
(\%)\end{array}$ & $\begin{array}{c}\text { Over-shoot } \\
(\%)\end{array}$ & Undershoot (\%) & $\begin{array}{l}\text { Settling Time } \\
(\mathrm{ms})\end{array}$ & $\begin{array}{c}\text { Ripple } \\
\text { voltage } \\
\text { (V) }\end{array}$ \\
\hline PID & 19.52 & 328.575 & 30.088 & 10.986 & 12.444 & 0.95 & 0.8 \\
\hline FOPID & 40.298 & 130.710 & 24.56 & 3.850 & 6.042 & 0.8 & 0.5 \\
\hline SMC & 394.54 & 20.199 & 0.505 & 0.505 & - & 0.3 & 0.01 \\
\hline
\end{tabular}




\section{Transient Response Analysis of PID, Fractional PID and SM Type Controllers}

In order to analysis the effect of the controller under a dynamic variation, better understanding of the controller performance can be viewed from the Fig. 26. The response of the system with different controllers during transient period is shown in these figures. The large overshoot and voltage ripples can be seen for PID and FOPID controller. A smooth response achieved using SM controller only. Fig. 26, shows the transient period during which the input voltage is changes from $12 \mathrm{~V}$ to $24 \mathrm{~V}$ for buck converter. The response of SM controller is ripple free and having negligible overshoot. The conventional PID shows large transition at $1 \mathrm{sec}$ and have voltage recursion to $5.7 \mathrm{~V}$. FOPID gives the response with large voltage ripples which not desirable. The SM controller is effectively managing the dynamic changes and able to keep the voltage at $5 \mathrm{~V}$ with negligible ripples and overshoot. Fig. 27 shows the transient period of boost converter for the variation of input voltage from $5 \mathrm{~V}$ to $8 \mathrm{~V}$. Response clearly describes the supremacy of the SM controller. Fig. 28 shows the transient period of buck-boost converter response when the input voltage increases from $12 \mathrm{~V}$ to $15 \mathrm{~V}$.The $\mathrm{SM}$ controller performs well. The Fig. 29 shows the transient period of DISO converter. The PID and FOPID controllers' shows large oscillations and it never settles at desired voltage. The SM controller settles at desired voltage of $10 \mathrm{~V}$ without any oscillation even with dynamic changes of input. These transient responses reveal the efficiency and effectiveness of SM controller compared with PID and FOPID controllers.
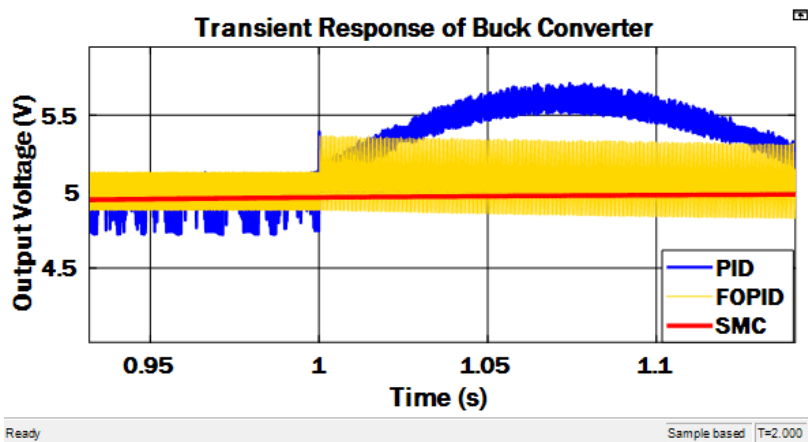

Fig. 26. Transient response of buck converter for a sudden change in input voltage from $12 \mathrm{~V}$ to $24 \mathrm{~V}$

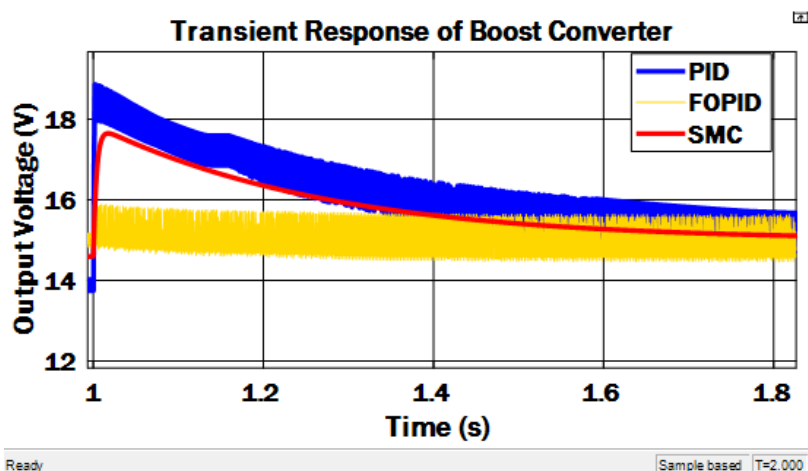

Fig. 27. Transient response of boost converter for a sudden change in input voltage from $5 \mathrm{~V}$ to $8 \mathrm{~V}$

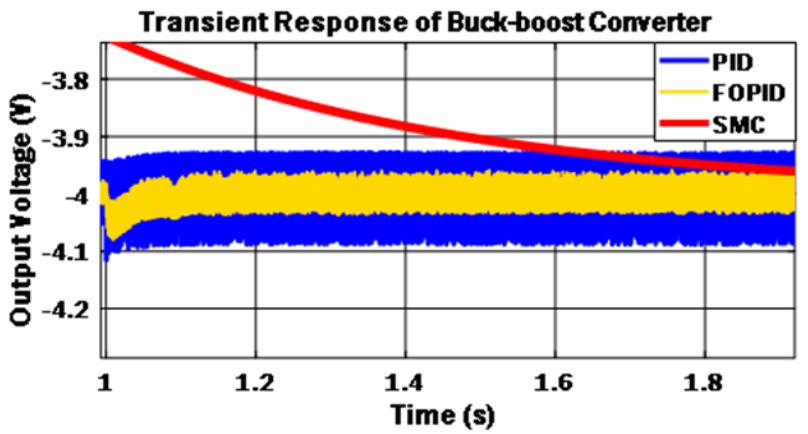

Fig. 28. Transient response of buck-boost converter for a sudden change in input voltage from $12 \mathrm{~V}$ to $15 \mathrm{~V}$

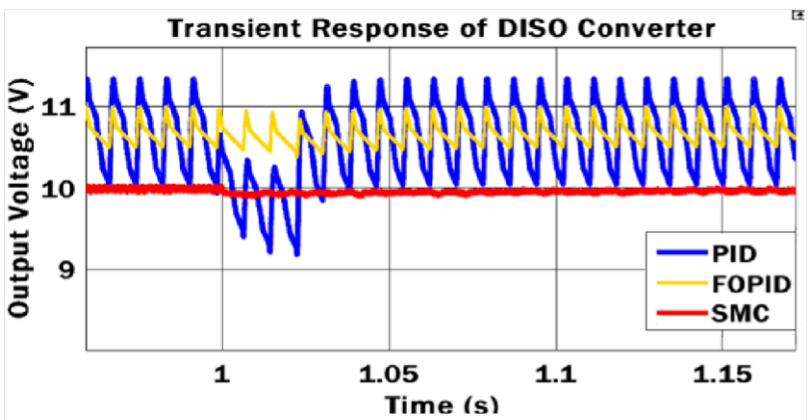

Fig. 29. Transient response of DISO converter for a sudden change in input voltage from $12 \mathrm{~V}$ to $24 \mathrm{~V}$

\section{Conclusion}

The four dissimilar type dc to dc converters named as buck, boost, buck-boost and DISO converters are mathematically modelled in state space and sliding mode type controller is implemented. The comparative study of controller performances based on the important time domain specifications are carried out. The comparative study of the effectiveness of SMC with ordinary PID and FOPID controllers are presented. Regulated output with less steady state error, lesser settling time and negligible ripple is achieved using SM controller compared to other controllers. The steady state and transient performance are well improved with SMC. The transient analysis of converter gives the supremacy of the SM controller over other two controllers.

This is an Open Access article distributed under the terms of the Creative Commons Attribution License

\section{References}

[1] C. Edwards and S. K. Spurgeron, Sliding Mode Control: Theory and Applications. London, U.K.: Taylor \& Francis, 1998.

[2] R.D Middlebrook and S Cuk, "A general unified approach to modeling switching Converter Power stages," in Proc. IEEE PESC Rec., pp. 18-34, 1976
[3] S. Tan, Y. M. Lai and C. K. Tse, "General Design Issues of SlidingMode Controllers in DC-DC Converters," in IEEE Transactions on Industrial Electronics, vol. 55, no. 3, pp. 1160-1174, March 2008, doi: 10.1109/TIE.2007.909058. 
[4] S. H. Chincholkar, W. Jiang and C. Chan, "An Improved PWMBased Sliding-Mode Controller for a DC-DC Cascade Boost Converter," in IEEE Transactions on Circuits and Systems II: Express Briefs, vol. 65, no. 11, pp. 1639-1643, Nov. 2018, doi: 10.1109/TCSII.2017.2754292.

[5] J. M. Carrasco, J. M. Quero, F. P. Ridao, M. A. Perales and L. G. Franquelo, "Sliding mode control of a DC/DC PWM converter with PFC implemented by neural networks," in IEEE Transactions on Circuits and Systems I: Fundamental Theory and Applications, vol. 44, no. 8, pp. 743-749, Aug. 1997, doi: 10.1109/81.611271.

[6] J. Mahdavi, M. R. Nasiri, A. Agah and A. Emadi, "Application of neural networks and State-space averaging to DC/DC PWM converters in sliding-mode operation," in IEEE/ASME Transactions on Mechatronics, vol. 10, no. 1, pp. 60-67, Feb. 2005, doi: 10.1109/TMECH.2004.842227.

[7] Siew-Chong Tan, Y. M. Lai and C. K. Tse, "A unified approach to the design of PWM-based sliding-mode voltage controllers for basic DC-DC converters in continuous conduction mode," in IEEE Transactions on Circuits and Systems I: Regular Papers, vol. 53, no. 8, pp. 1816-1827, Aug. 2006, doi: 10.1109/TCSI.2006.879052.

[8] S. C. Tan, Y. M. Lai, C. K. Tse, and L. Martinez-Salamero, "Special family of PWM based sliding mode voltage controllers for basic dcdc converters in discontinous conduction mode," Electric Power Applications IET -2007, vol. 1, no. 1, pp. 64-74

[9] Aseem K, Selva Kumar S, Closed loop control of DC-DC converters using PID and FOPID Controllers, International Journal of Power
Electronics and Drive System (IJPEDS) Vol. 11, No. 3, September 2020, pp. 1323 1332 ISSN: 2088-8694, doi: 10.11591/ijpeds.v11.i3.pp1323-1332

[10] J. M. Carrasco, J. M. Quero, F. P. Ridao, M. A. Perales and L. G. Franquelo, "Sliding mode control of a DC/DC PWM converter with PFC implemented by neural networks," in IEEE Transactions on Circuits and Systems I: Fundamental Theory and Applications, vol. 44, no. 8, pp. 743-749, Aug. 1997.

[11] R. Saravanakumar and Jena, D., "Validation of an integral sliding mode control for optimal control of a three blade variable speed variable pitch wind turbine", International Journal of Electrical Power \& Energy Systems, vol. 69, pp. 421-429, 2015.

[12] K. Matthew and R. Saravanakumar, "Design of Double Integral Sliding Mode Control for Variable Speed Wind Turbine at Partial Load Region", in 2017 IEEE International Conference on Computational Intelligence and Computing Research (ICCIC), Coimbatore, India, 2017.

[13] V. Vijayakumar, R. Divya, and A. Vivek, "Sliding mode controlled quadratic boost converter", in International Conference on Computation of Power, Energy, Information and Communication (ICCPEIC), 2014, Chennai, 2014.

[14] Y. He and F. L. Luo, "Sliding-mode control for dc-dc converters with constant switching frequency," in IEE Proceedings - Control Theory and Applications, vol. 153, no. 1, pp. 37-45, 16 Jan. 2006. 